Article

\title{
Small-Scale Rainfall Variability Impacts Analyzed by Fully-Distributed Model Using C-Band and X-Band Radar Data
}

\author{
Igor Paz ${ }^{1,2, *} \mathbb{C}_{\text {, Bernard Willinger }}{ }^{3}$, Auguste Gires ${ }^{1}{ }^{1}$, Bianca Alves de Souza ${ }^{1,2}$, \\ Laurent Monier ${ }^{4}$, Hervé Cardinal ${ }^{5}$, Bruno Tisserand ${ }^{6}$, Ioulia Tchiguirinskaia ${ }^{1}$ and \\ Daniel Schertzer ${ }^{1}$ (1) \\ 1 HMCO, Ecole des Ponts ParisTech, University of Paris-Est, 77455 Champs-sur-Marne, France; \\ auguste.gires@enpc.fr (A.G.); biancasouza.ime@gmail.com (B.A.d.S.); ioulia.tchiguirinskaia@enpc.fr (I.T.); \\ daniel.schertzer@enpc.fr (D.S.) \\ 2 Instituto Militar de Engenharia, Praça General Tibúrcio 80, Praia Vermelha, Rio de Janeiro 22290-270, Brazil \\ 3 Veolia Eau Ile-de-France, 91300 Massy, France; bernard.willinger@veolia.com \\ 4 Direction Technique et Performance, Veolia, 30 rue Madeleine Vionnet, 93300 Aubervilliers, France; \\ laurent.monier@veolia.com \\ 5 SIAVB, Syndicat Intercommunal pour l'Assainissement de la Vallée de la Bièvre, 91370 Verrières-le-Buisson, \\ France; h.cardinal@siavb.fr \\ 6 Veolia Recherche et Innovation, 78600 Maisons-Laffitte, France; bruno.tisserand@veolia.com \\ * Correspondence: igor.da-silva-rocha-paz@enpc.fr
}

Received: 7 May 2019; Accepted: 13 June 2019; Published: 18 June 2019

\begin{abstract}
Recent studies have highlighted the need for high resolution rainfall measurements for better modelling of urban and peri-urban catchment responses. In this work, we used a fully-distributed model called "Multi-Hydro" to study small-scale rainfall variability and its hydrological impacts. The catchment modelled is a semi-urban area located in the southwest region of Paris, an area that has been previously partially validated. At this time, we make some changes to the model, henceforth using its drainage system globally, and we investigate the influence of small-scale rainfall variability by modelling three rainfall events with two different rainfall data inputs: the C-band radar data provided by Météo-France at a $1 \mathrm{~km} \times 1 \mathrm{~km} \times 5 \mathrm{~min}$ resolution, and the new X-band radar (recently installed at Ecole des Ponts, France) data at a resolution of $250 \mathrm{~m} \times 250 \mathrm{~m} \times 3.41$ min, thereby presenting the gains of better resolution (with the help of Universal Multifractals). Finally, we compare the Multi-Hydro hydrological results with those obtained using an operational semi-distributed model called "Optim Sim" over the same area to revalidate Multi-Hydro modelling, and discuss the model's limitations and the impacts of data quality and resolution, observing the difficulties associated with semi-distributed models when accounting the spatial variability of weather radar data. This work concludes that it may be useful in future to improve rainfall data acquisition, aiming for better spatio-temporal resolution (now achieved by the weather dual-polarized X-band radars) and data quality when considering small-scale rainfall variability, and to merge deterministic, fully-distributed and stochastic models into a hybrid model which would be capable of taking this small-scale rainfall variability into account.
\end{abstract}

Keywords: small scale; rainfall variability; X-band radar; fully-distributed model; multi-hydro; multifractals

\section{Introduction}

The urban population in 2014 accounted for $54 \%$ of the total global population [1]; by the deadline of the new Sustainable Development Goals (SDGs [2]) in 2030, 60\% of all people will reside 
in cities, proportionally twice that of 1950 [3]. Some of the changes in many extreme weather and climate events have been linked to human influences, including the number of heavy precipitation events in a number of regions [4]. This growing urbanization, which typically creates impervious surface areas with hydraulically efficient drainage results in much faster drainage than in natural areas $[5,6]$, and consequently, has the potential to produce huge floods, threatening human security and infrastructure integrity [7-11]. In order to manage its impacts and their consequences, continuous simulations are required $[12,13]$.

The study of water flows in urbanized catchments is crucial to saving human lives and for environmental protection and infrastructure safety, and has clearly been gaining in importance over the past few decades [11-19]. However, the high heterogeneity of urban areas, difficulties in measuring the physical parameters and defining the limits of the catchment, and the interaction of hydrological processes on various spatio-temporal scales make hydrological modelling a complex task [11]. Even with the recent increases of computational power and resolution of distributed data, such as altitude, precipitation and land use, understanding hydrological behavior remains a challenge.

In addition, as fine spatio-temporal resolution of rainfall data becomes mandatory for accurate model validation and exploitation $[11,18,19]$, weather radar data have been increasingly applied to hydrological models due to their ability to spatio-temporally estimate rainfall fields, compared to the common sparseness of rain gauge networks. Although they do not directly measure precipitation rates (as rain gauges do), meteorological radars provide spatiotemporal precipitation estimates. However, these estimates, initially based on the reflectivity, have some significant uncertainties. To reduce these uncertainties, especially for high rainfall intensities, recent dual polarization technology has been used to directly estimate rainfall intensities through specific differential phase (KDP) values [20-22].

Furthermore, there are different types of hydrological models; those dealing with urban stormwater are usually characterized as semi-distributed or fully-distributed models [23,24]. The former generally comprizes conceptual models divided in sub-catchments requiring careful calibration. The latter, usually physically based and generally more realistic, are two-dimensionally-discretized with a land use unit being attributed to each surface pixel. Considering developments in computer capabilities and the availability of remote sensing data, the use of distributed hydrological models to better take into account rainfall variability is becoming more widespread [11].

This work presents a hydrological study of the Jouy-en-Josas catchment, a $3 \mathrm{~km}^{2}$ semi-urbanized area located in the southwest region of Paris. Firstly, we took the hydrological modelling of this case study previously calibrated by Gires et al. [25] using the Multi-Hydro model [24,26,27], a physically-based, fully-distributed model currently under development at Ecole des Ponts ParisTech which is able to account for the high heterogeneity of urban and semi-urban regions and rainfall spatio-temporal variability on different scales. Then, we made some improvements to the model and obtained new hydrological simulations for three more recent events, comparing $\mathrm{C}$ - and $\mathrm{X}$-band radar rainfall data with the help of a statistical analysis using Universal Multifractals [28]. We can subdivide this work approach into three main parts. The first consists of improving the generation of rainfall rates introduced into the model; the second comprizes considering the totality of the sewer system of the catchment (Gires et al. [25] had previously considered only $60 \%$ of it); and the third is an analysis of the hydrological impacts of small-scale rainfall variability using X-and C-band radar data at different resolutions. Finally, we compared the results of the Multi-Hydro hydrological simulations at the outfall of the Jouy-en-Josas catchment to those obtained using operational software (Optim Sim) managed by the SIAVB ("Syndicat Intercommunal pour l'Assainissement de la Vallée de la Bièvre", a local authority in charge of the upper Bièvre River catchment) to revalidate the totality of the catchment sewer system. This comparison highlights the models' limitations and the impacts of data quality and resolution, bringing into the discussion the difficulties associated with semi-distributed models when considering the spatial variability of weather radar data.

This paper is organized as follows. Section 2 presents the case study, selected storm events and rainfall data, and a statistical analysis of the rainfall data is performed with the help of Universal 
Multifractals. In Section 3, the hydrological modelling is detailed. Finally, a discussion is presented in Section 4.

\section{Materials and Methods}

\subsection{Case Study}

The site of Jouy-en-Josas is a sub-catchment of the Bièvre catchment, located in the South-West of the Paris region at the convergence point of three counties: Essone, Yvelines and Hauts-de-Seine. The Bièvre is a $33 \mathrm{~km}$-long river and an tributary of the Seine River. The first $18 \mathrm{~km}$ upstream (from Saint-Quentin-en-Yvelines to Antony) is open, before being channeled into the SIAAP ("Syndicat Interdépartemental pour l'Assainissement de l'Agglomération Parisienne", a French public administrative institution that manages metropolitan Paris sewer system) network with outflow limited to $12 \mathrm{~m}^{3} / \mathrm{s}$ by convention. The Bièvre catchment has an area of approximately $110 \mathrm{~km}^{2}$ and currently houses around 130,000 inhabitants. It encompasses the $18 \mathrm{~km}$ upstream part of the Bièvre River and another $15 \mathrm{~km}$ of its tributaries, and has been related to the main floods of the Seine River in the past century. The most well-known occurred in January 1910, when hundreds of streets were flooded and over 14,000 buildings were affected in Paris [29]. In the Bièvre Valley specifically, there were two other major floods with catastrophic consequences: 1973 and 1982. In the latter, in only three hours, $110 \mathrm{~mm}$ precipitation was recorded over the Bièvre Valley, of which $80 \mathrm{~mm}$ occurred in just 40 minutes. At that time, it was estimated that 10 million $\mathrm{m}^{3}$ of water left as run-off, 2 million $\mathrm{m}^{3}$ discharged downstream, $500,000 \mathrm{~m}^{3}$ was stored in ponds and 7.5 million $\mathrm{m}^{3}$ invaded the valley. The Jouy-en-Josas sub-catchment modelled in this paper with Multi-Hydro has an area of $3.017 \mathrm{~km}^{2}$, and borders the Bièvre River (mostly on its left bank and with a small portion on its right). Figure 1: on the bottom, the Bièvre catchment divided into 27 sub-catchments; on the top, the Jouy-en-Josas area, which is mostly composed of the JOUY2 sub-catchment and a smaller woodland area of the JOUY1 sub-catchment.

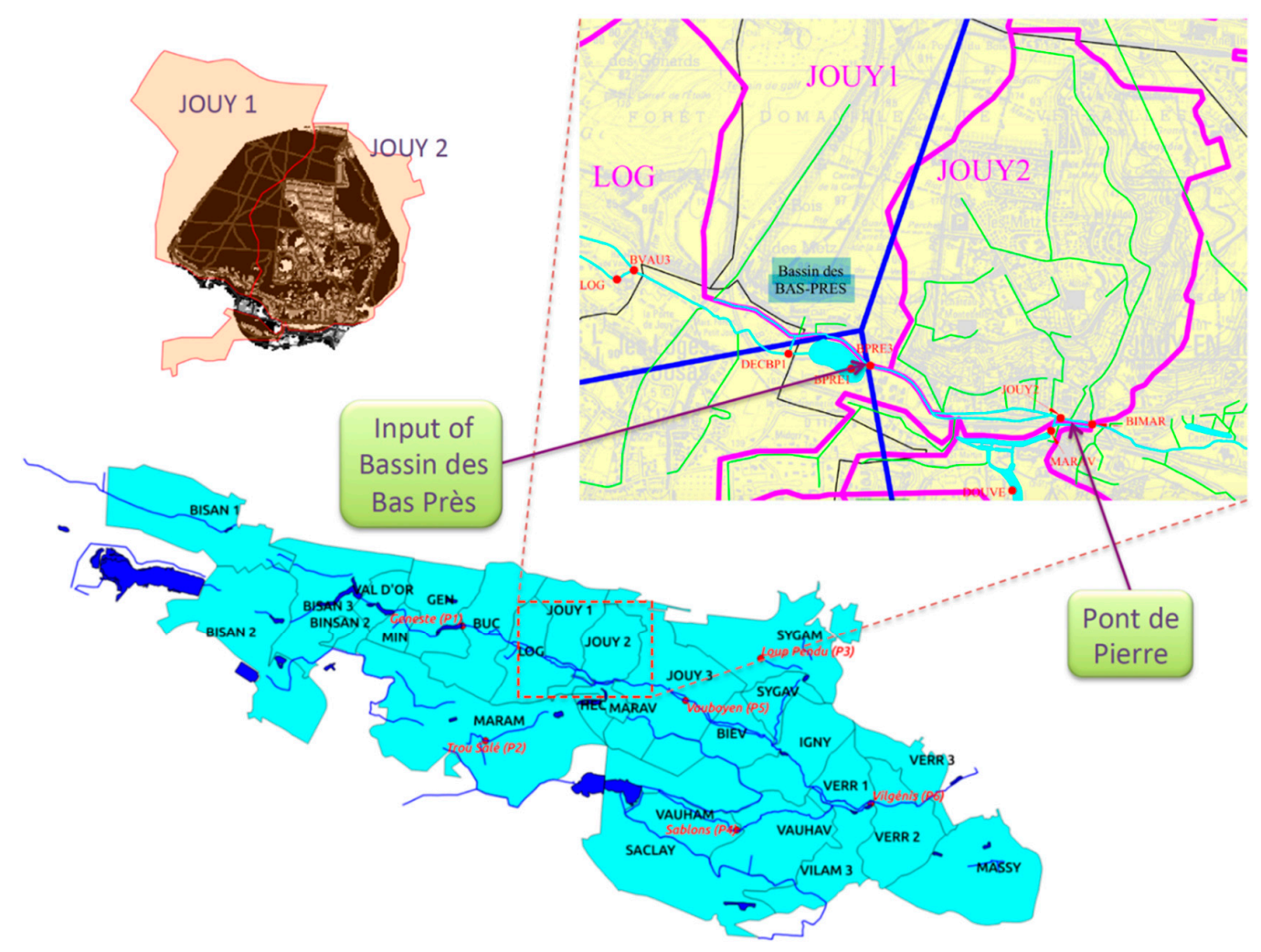

Figure 1. Representation of the Bièvre catchment divided into 27 sub-catchments with six rain gauges represented by red dots (bottom) and the Jouy-en-Josas area (top). 


\subsection{Storm Events and Rainfall Data}

In this work, we chose three rainfall events for study: 12-13/09/2015, 16/09/2015 and 05-06/10/2015. In the months following the inauguration of the X-band radar at Ecole des Ponts (9 June, 2015 [30]), there was a protracted dry period. Nevertheless, in September 2015, two distinct weather phenomena arrived in France. The first and strongest (up to $389 \mathrm{~mm}$ was measured in Ardèche in $48 \mathrm{~h}$ ) was a Mediterranean type episode, occurring on the 12-13 September 2015 (data source: Météo-France). The second (with $34.2 \mathrm{~mm}$ registered in Fontainebleau), occurring on 16 September 2015, caused particularly strong winds and storms around the Lyon region during the "Henri" cyclone (data source: Météo-France). We analyzed these two rainfall events, as well as another one which occurred on 5-6 October 2015; all three were chosen taking into account their hydrological impact on the SIAVB-Bièvre catchment in order to cover the most common meteorological situations in the region, combining stratiform and convective rainfall occurrences [31]. Additionally, these rainfall events lasted, in total, almost $90 \mathrm{~h}$, and were deliberately not divided into several successive rainy periods, as this would artificially increase their numbers. This means that the chosen rainfall events are sufficiently representative for the purposes of this study.

Two different weather radar rainfall data were analyzed. One of them was from the Météo-France C-band radar located at Trappes, France. Météo-France provides a radar mosaic which covers the entire country, being a product initially of the Aramis project [32], and later, of the PANTHER project (Aramis New Technologies Hydrometeorology Extension and Renewal). The latter is, in fact, a network of 29 radars (Figure 2). However, as the farthest part of the studied catchment is about $25 \mathrm{~km}$ from the Trappes radar, we can consider that this one alone will contribute to the analyzed data.
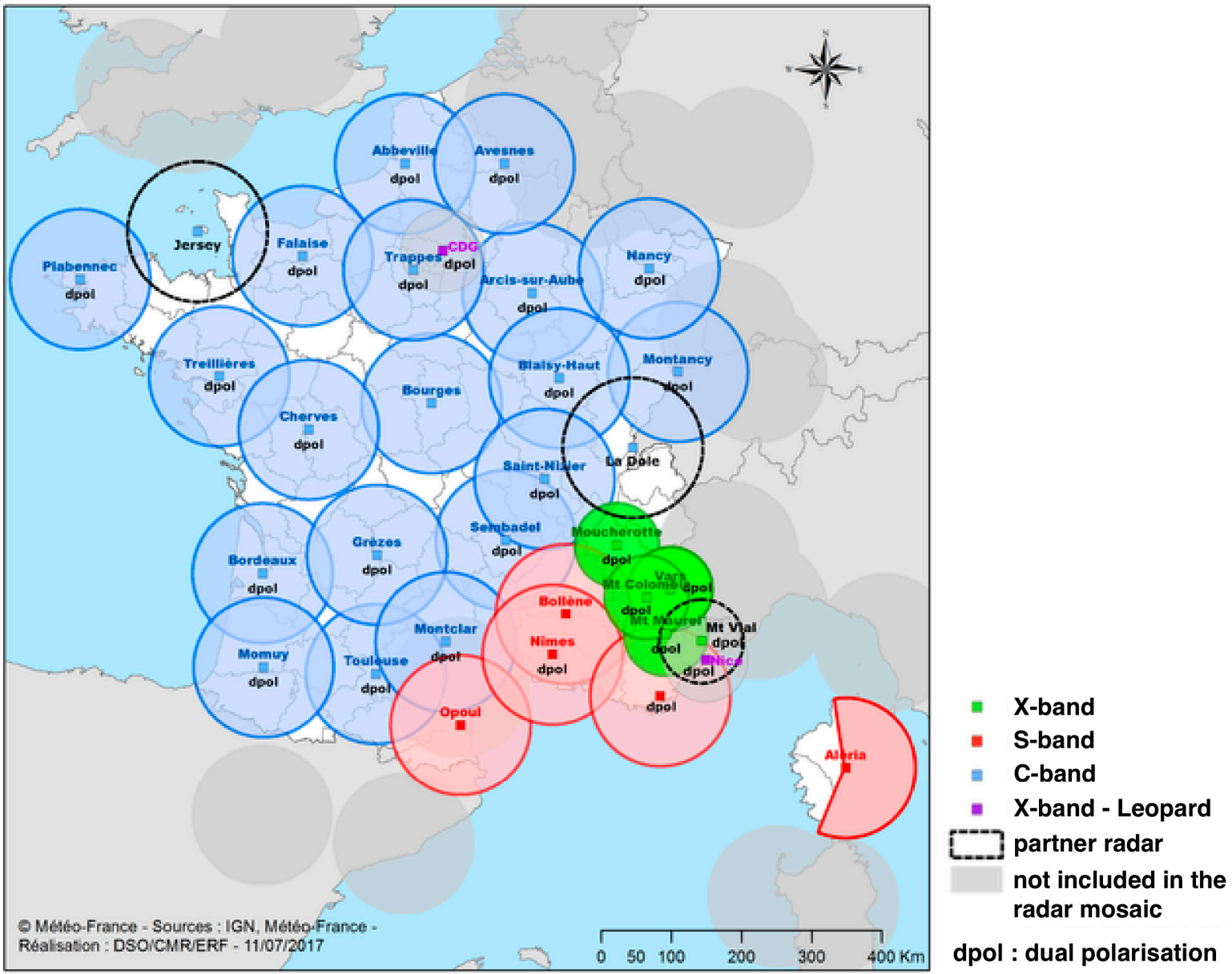

Figure 2. The Météo-France radar network (courtesy Météo-France). 
This mosaic product has a temporal resolution of $5 \mathrm{~min}$ and a spatial one of $1 \mathrm{~km}$. The data is obtained as reflectivity (dBZ) and then, after applying some filters and other post-treatments, it is transformed into rainfall intensity $(\mathrm{R}$, in $\mathrm{mm} / \mathrm{h})$ using the Marshall-Palmer Z-R equation [33] with fixed parameters: $a=200$ and $b=1.6$.

$$
Z=a R^{b}
$$

In addition, a real-time calibration is performed over the Météo-France C-band radar data, based on a comparison between local rain gauges and collocated radar pixels from the last $12 \mathrm{~h}$, adjusting the 5-min radar rainfall accumulation field [34,35].

The second mentioned type of rainfall data to be analyzed was obtained from the Ecole des Ponts' recently installed X-band radar, located at Champs-sur-Marne, France. This was processed using software developed by Selex, called Rainbow (Selex copyright). There are a number of different products, but in this work we used the DPSRI (Dual Polarization Surface Rainfall Intensity) (see Figure 3 for illustration).

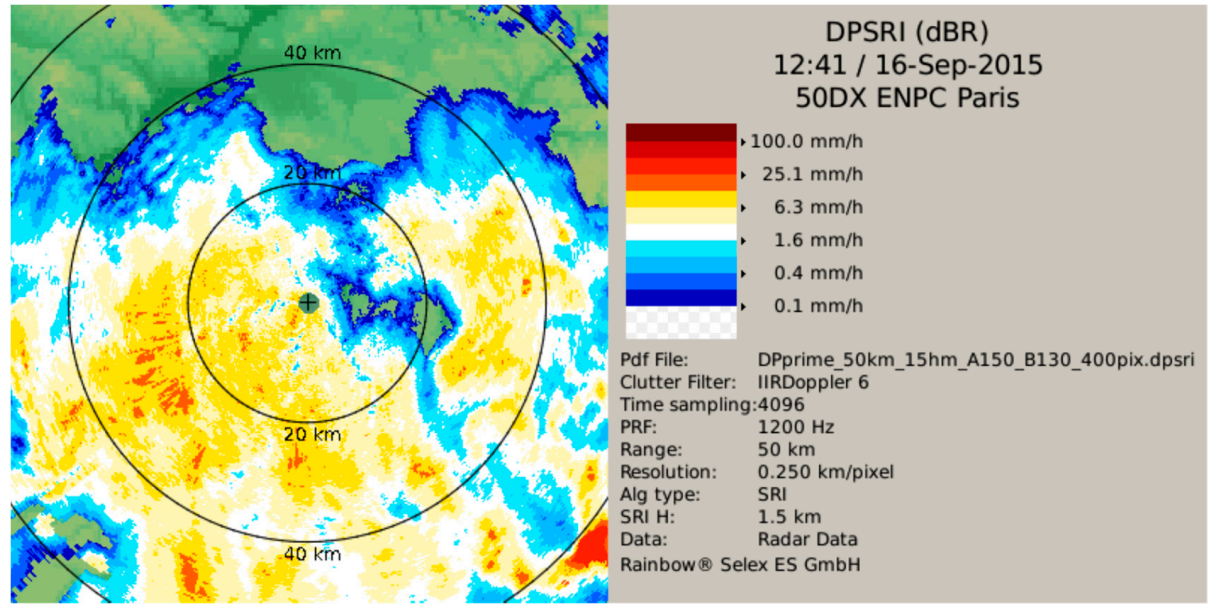

Figure 3. Icon of the standard Rainbow software (Selex copyright): DPSRI product of rainfall intensity.

The spatio-temporal resolution is variable, mainly due to two factors: pulse width and angle step. Given the chosen parameters, the temporal resolution is $3.4 \mathrm{~min}$ and the spatial resolution is $250 \mathrm{~m}$. In contrast to the C-band radar product, the DPSRI is obtained in rainfall intensity ( $\mathrm{R}$, in $\mathrm{mm} / \mathrm{h})$. In fact, for very low intensities, it is generated from $\mathrm{dBZ}$ (then the Z-R relationship is applied), while for higher intensities, it is generated from dual-polarization data (the Specific Differential Phase KDP) [36].

$$
R=19.63\left|K_{D P}\right|^{0.823}, \quad \text { for } Z>35 d B Z \text { and } K_{D P}>0.3^{\circ} / k m
$$

A summary of the characteristics of the selected storm events and the studied radar data is presented in Table 1. Figure 4 displays the temporal evolution of the average rain rate and cumulative depth over the Jouy-en-Josas area, and Figure 5 presents the accumulated rainfall depths by radar pixels over the catchment area for the Météo-France C-band radar product and the ENPC X-band DPSRI.

Table 1. Characteristics of selected storm events and radar rainfall data.

\begin{tabular}{clccccc}
\hline Events & Radar & $\begin{array}{c}\text { Space } \\
\text { Resolution }\end{array}$ & $\begin{array}{c}\text { Time } \\
\text { Resolution }\end{array}$ & $\begin{array}{c}\text { Space Grid } \\
\text { Dimension }\end{array}$ & $\begin{array}{c}\text { Time } \\
\text { Duration }\end{array}$ & Time Steps \\
\hline $12 / 13-09-2015$ & C-band & $1 \mathrm{~km}$ & $5 \mathrm{~min}$ & $64 \times 64$ & $44 \mathrm{~h}$ & 528 \\
$12 / 13-09-2015$ & X-band & $250 \mathrm{~m}$ & $3.41 \mathrm{~min}$ & $256 \times 256$ & $44 \mathrm{~h}$ & 773 \\
$16-09-2015$ & C-band & $1 \mathrm{~km}$ & $5 \mathrm{~min}$ & $64 \times 64$ & $11.3 \mathrm{~h}$ & 136 \\
$16-09-2015$ & X-band & $250 \mathrm{~m}$ & $3.41 \mathrm{~min}$ & $256 \times 256$ & $11.3 \mathrm{~h}$ & 199 \\
$5 / 6-10-2015$ & C-band & $1 \mathrm{~km}$ & $5 \mathrm{~min}$ & $64 \times 64$ & $31 \mathrm{~h}$ & 372 \\
$5 / 6-10-2015$ & X-band & $250 \mathrm{~m}$ & $3.41 \mathrm{~min}$ & $256 \times 256$ & $31 \mathrm{~h}$ & 545 \\
\hline
\end{tabular}



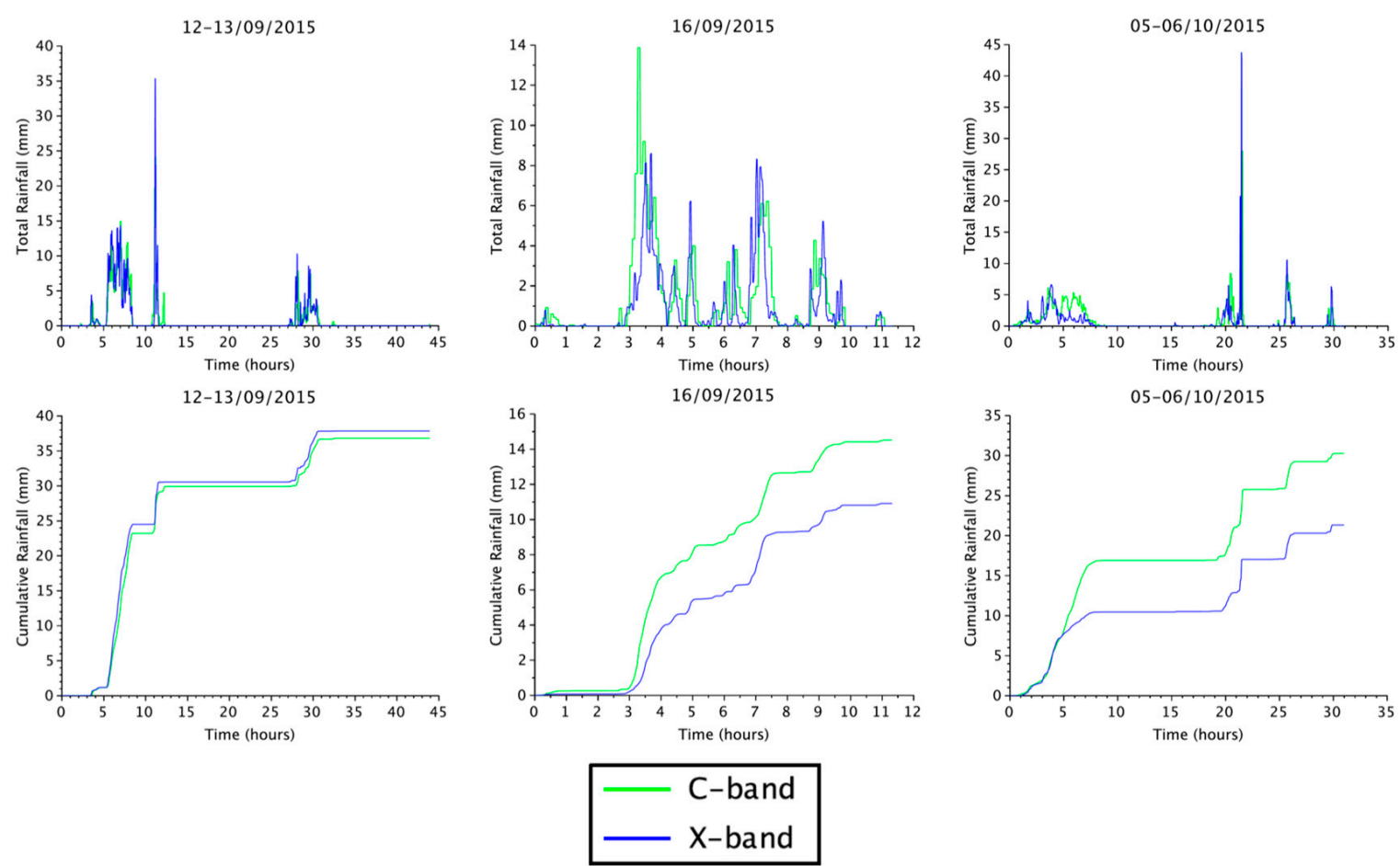

Figure 4. Time evolution of rain rate (top) and cumulative depth (bottom) over the whole Jouy-en-Josas sub-catchment area for the two data types (C-band, in green; and X-band, in blue) for the three events: 12-13 September 2015 (left), 16 September 2015 (centre) and 5-6 October 2015 (right).

For the 12-13 September event, the second peak of the total rainfall series (approximately $12 \mathrm{~h}$ after the beginning of the event) was higher for the X-band radar data. Nevertheless, the cumulative rainfall series are very similar for both radars (with the X-band one being even slightly higher). Additionally, with regard to the accumulated rainfall depths, one may verify the spatial intermittency of the pixel values for both radar data types (much more noticeable on the X-band ones). For the 16 September event, the C-band cumulative rainfall series was higher than the X-band one. At between 3 and $4 \mathrm{~h}$ into this event, the peak total rainfall series was higher for the C-band radar data. However, the peak at around $7 \mathrm{~h}$ was just slightly higher for the $\mathrm{X}$-band radar data. Furthermore, there was a higher intermittency for the $\mathrm{X}$-band accumulated rainfall depths. For the last event, there was an important difference in the beginning of the event in the cumulative rainfall series, with a cumulative depth that was approximately $6 \mathrm{~mm}$ higher for the C-band radar data, increasing to $8 \mathrm{~mm}$ at the end of the event. Nevertheless, the last three peaks in the total rainfall series were higher for the X-band radar data. Once again, the intermittency of the accumulated rainfall depths was more remarkable for the X-band radar data.

Additionally, unlike the work previously developed by Gires et al. [25], there were no more local measurements at the Pont de Pierre (see Figure 1) for the period of these three selected events. So, in order to compare the hydrological simulations, an operational software called Optim Sim (see Section 3.1.2)—managed by Veolia for the SIAVB in Massy (a small town inside the Bièvre Valley in the south of Paris region) - was used to simulate the same three events with the C-and X-band radar data and two other types of rainfall data: the SIAVB network of six rain gauges (Figure 1), and the CALAMAR ("CAlcul de LAMes d'eau à l'Aide du Radar" (Calculating Rain with the Aid of Radar)) product $[37,38]$. The latter is a system developed by RHEA SAS Company for treating (by gauge adjustment) and diffusing the radar data produced by Météo-France. The image calibration is done in such a way that a rain gauge and its corresponding radar image pixel show approximately the same rainfall value. The operational spatio-temporal resolution is $1 \mathrm{~km}^{2}$ and $5 \mathrm{~min}$. It provides real-time measurement sand also enables a rainfall event to be reconstructed through its off-line mode [39]. 

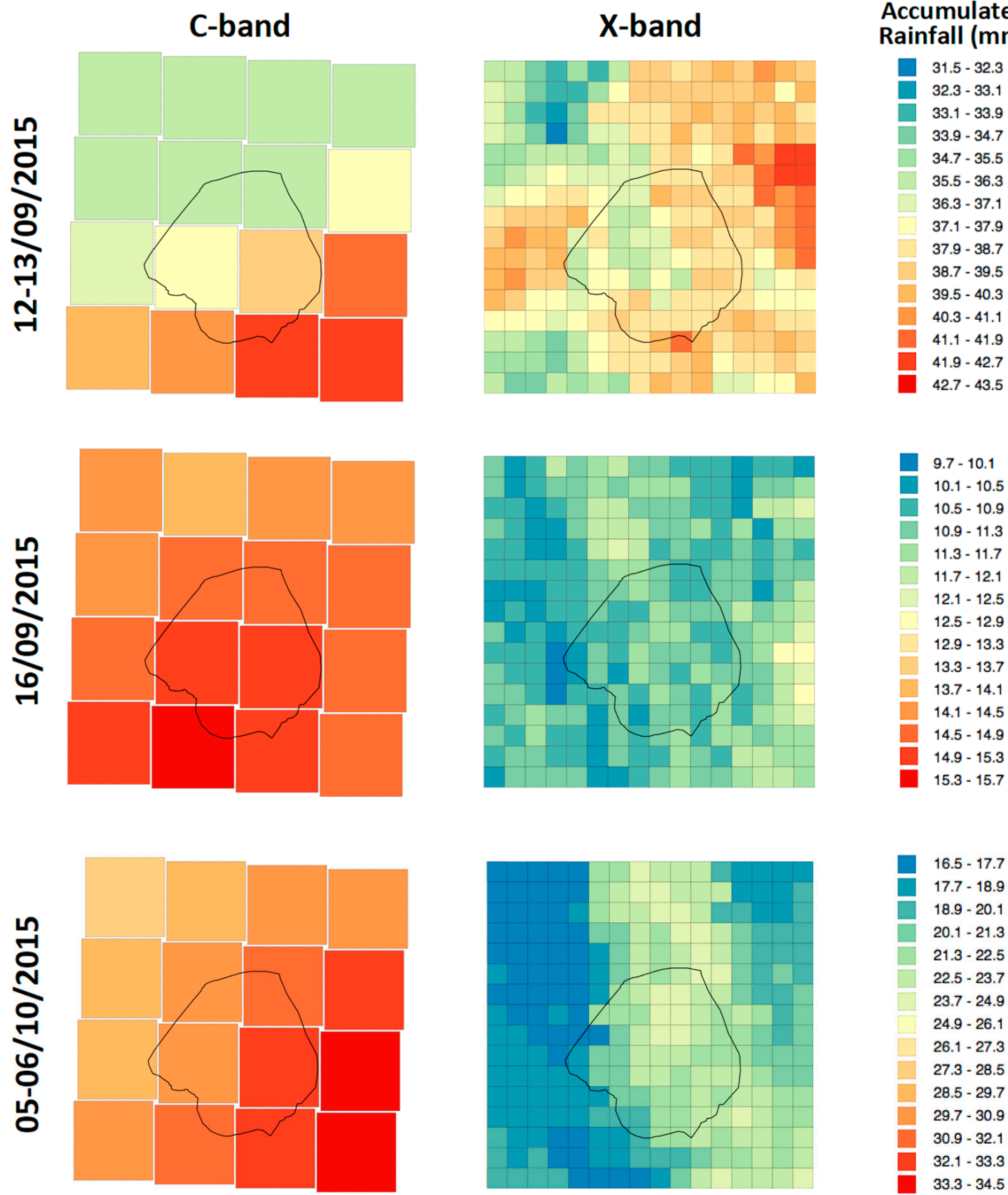

Figure 5. Accumulated rainfall depths by radar pixels over the Jouy-en-Josas sub-catchment area for both the $\mathrm{C}$-and $\mathrm{X}$-band radar data for the three studied events.

For the Bièvre River catchment, the CALAMAR images are firstly calibrated in a broader area (left side of Figure 6) and then recalibrated in real-time using the six SIAVB rain gauges over the Bièvre catchment area (right side of Figure 6). Furthermore, it is important to point out that the operational software Optim Sim has been calibrated over the whole Bièvre catchment using the CALAMAR (which will be used in this work as reference for the comparison of hydrological results in Section 3.2) and SIAVB rain gauge rainfall data. 


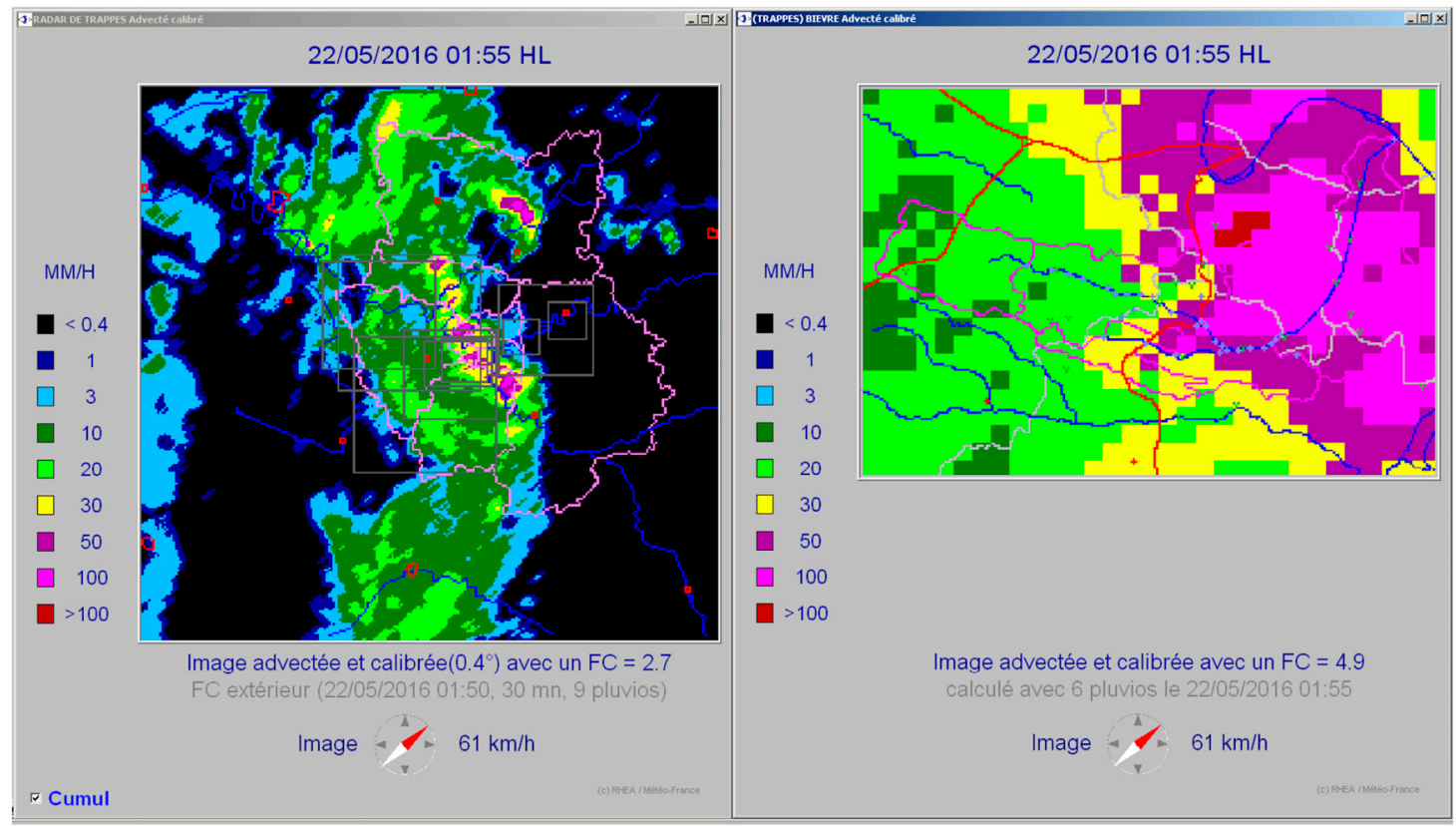

Figure 6. Illustration of a CALAMAR image (CVeolia) over the Ile-de-France region (left) and zoomed in over the Bièvre catchment (right).

\subsection{Multifractal Analysis}

Rainfall has been widely analyzed as a multifractal field [17,28,40-53]. Schertzer and Lovejoy [28] used an approach introducing the formalism of turbulence (modelling the rainfall variability by a multiplicative cascade process, assuming the transfer of energy from larger to smaller scales, similar to what happens in turbulence models) and developed the Universal Multifractal (UM) model.

Considering $\varepsilon_{\lambda}$, a multifractal field at the resolution $\lambda\left(=\frac{L}{l}\right)$ defined by the ratio between the outer scale of the phenomenon and the observation scale, the statistical moment of its $q$ th power exhibits scaling behavior [28]:

$$
\left\langle\varepsilon_{\lambda}^{q}\right\rangle \approx \lambda^{K(q)}
$$

where $K(q)$ is the scaling moment function, $<>$ denotes the mathematical ensemble average, and $\approx$ means asymptotic equivalence.

In the framework of universal multifractals (UM), the $K(q)$ function is convex [54], and for conservative fields $\left(\left\langle\varepsilon_{\lambda}\right\rangle=1\right.$, i.e., $\left.K(1)=0\right)$ is described by just two independent UM parameters: $\alpha$ and $C_{1} . \alpha \in[0,2]$ is the Levy index measuring the degree of multifractality (i.e., the deviation from multifractality), where $\alpha=0$ corresponds to a monofractal field and $\alpha=2$ to the extreme log-normal case. $C_{1} \in[0, d]$, with $d$ being the dimension of the support ( $d=2$ in this case), is the mean intermittency of the field ( $C_{1}=0$ for a homogeneous field). $K(q)$ is given by:

$$
K(q)= \begin{cases}\frac{C_{1}}{\alpha-1}\left(q^{\alpha}-q\right), & \alpha \neq 1 \\ C_{1} q \log (q), & \alpha=1\end{cases}
$$

The parameters $\alpha$ and $C_{1}$ are estimated by using the double trace moment (DTM) technique [55]. This technique is particularly valuable in the framework of $U M$, based on the fact that the scaling moment function $K(q, \eta)$ of the field $\varepsilon_{\lambda}^{(\eta)}$, obtained by degrading the $\eta$ th power of the field at the finest resolution, is easily expressed in terms of $\alpha$ :

$$
\left\langle\left(\varepsilon_{\lambda}^{(\eta)}\right)^{q}\right\rangle \approx \lambda^{K(q, \eta)}=\lambda^{\eta^{\alpha} K(q)}
$$


Thus, $\alpha$ can be estimated as the slope of the linear part of the $\log$-log graphic of $K(q, \eta)$ by $\eta$ for fixed $q$ [42]. Finally, considering that $K(q, 1)$ is the intersection of the slope with $\log (\eta)=0$, it is possible to determine $C_{1}$.

In this section, we estimated the UM parameters $\alpha$ and $C_{1}$ over a $64 \mathrm{~km} \times 64 \mathrm{~km}$ area for each of the three events from both the $\mathrm{C}$ - and X-band radar data studied in this work independently, by using the DTM method on ensemble analysis over the entirety of the rainfall events (with each time step being considered as an independent realization) (Table 2).

Table 2. UM parameters $\alpha$ and C1.

\begin{tabular}{cccc}
\hline Events & Radar & $\alpha$ & C1 \\
\hline $12 / 13-09-2015$ & C-band & 1.249 & 0.217 \\
$12 / 13-09-2015$ & X-band & 1.536 & 0.184 \\
$16-09-2015$ & C-band & 1.022 & 0.116 \\
$16-09-2015$ & X-band & 1.431 & 0.108 \\
$5 / 6-10-2015$ & C-band & 1.577 & 0.152 \\
5/6-10-2015 & X-band & 1.787 & 0.153 \\
\hline
\end{tabular}

As displayed in Table 2, the multifractality of $\alpha$ is considerably lower for C-band than for X-band radar data per event, for all three events. This indicates that the $\mathrm{X}$-band radar rainfall fields present greater peaks than the C-band ones, reinforcing the idea that enhancement of the radar data resolution improves the ability to detect high rainfall intensities. On the other hand, the mean singularity $C_{1}$ estimates are very similar for both the $\mathrm{C}$ - and $\mathrm{X}$-band radar data per event, which would mean similar rainfall cumulus over the $64 \mathrm{~km} \times 64 \mathrm{~km}$ area. However, the lower rainfall cumulus, especially for the last two events, for the $\mathrm{X}$-band compared to the $\mathrm{C}$-band radar data, might be related to a difference in linear pre-factors, as suggested by Alves de Souza et al. [56].

\section{Results}

\subsection{Hydrological Modelling}

\subsubsection{Multi-Hydro Description and Implementation}

Multi-Hydro is a fully-distributed model which is under development at Ecole des Ponts [24,26,27]. It is an interface platform that allows interaction to occur between four open source packages (surface, ground, drainage and rainfall modules) that simulate different parts of the water cycle in urban catchments. The TREX (Two Dimensional Runoff Export, [57]) surface module is used, a model developed at the Colorado University. The ground module employed is the VS2DT (Variably Saturated 2-Diimensional flow and Solute Transport, [58]) model, developed by USGS (the United States Geological Survey). The drainage module is based on SWMM (Storm Water Management Model, [59]), developed by the US Environmental Agency.

Finally, the rainfall module enables Multi-Hydro to work with different types of rainfall data (rain gauges, radar and downscaled radar data). However, the VS2DT model was not connected for this study because of its time-consuming computation.

The Jouy-en-Josas case study was modelled with a 10-m spatial resolution; the land use area (Figure 7) was generated by considering only the priority rule [24,56]. The storm water sewer system (Figure 8) is discharged into the Bièvre River, which was also modelled as a pipe. Additionally, in contrast to the primary work of Gires et al. [25] that considered the measurement point of water depth at the "Pont de Pierre" (which has been disabled since 2014), the outlet of the catchment was taken here as the comparison point. This therefore validates the whole catchment at this time, and not only the previous $60 \%$ of it, as was the case in Gires et al. [25]. 


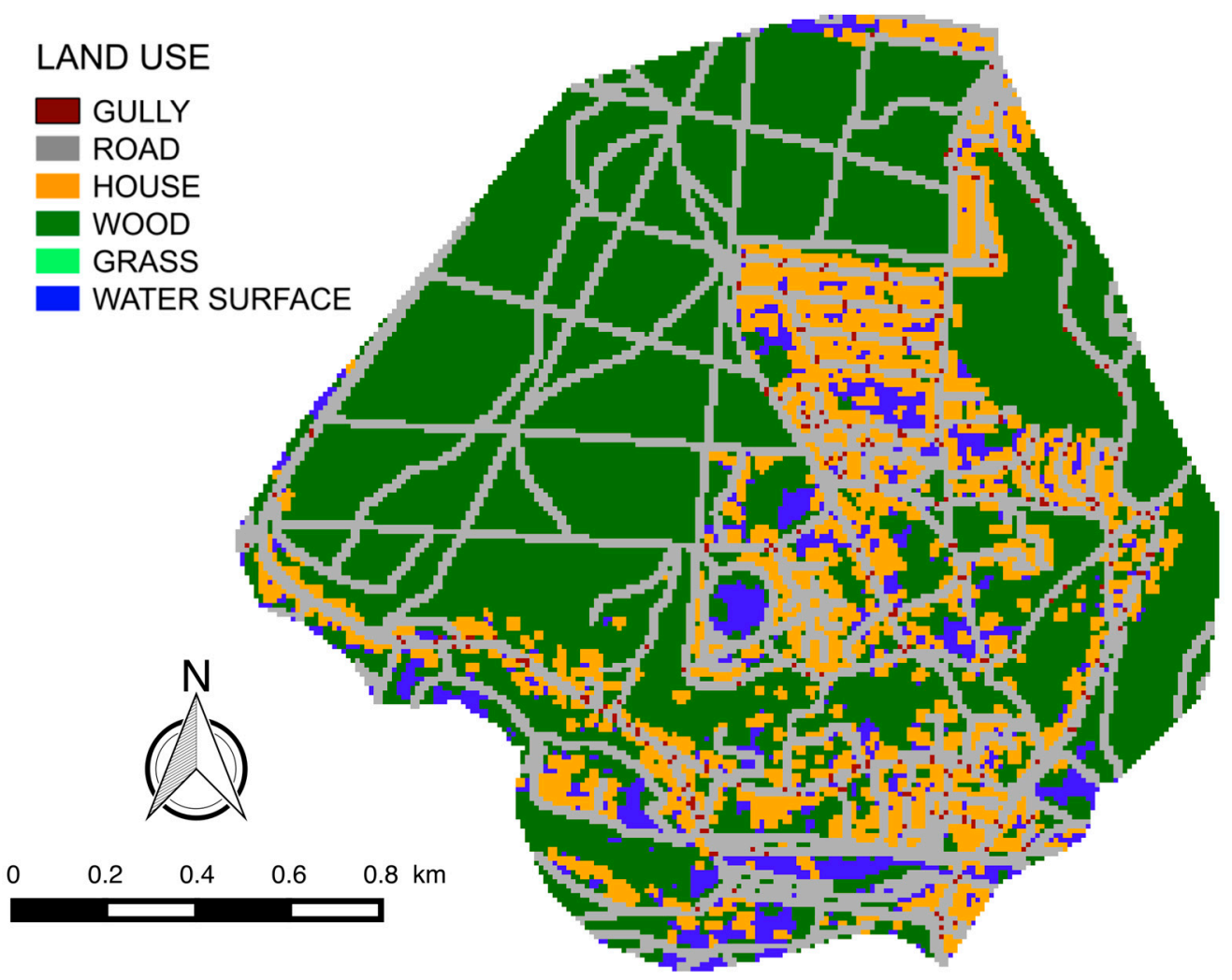

Figure 7. Land use of Jouy-en-Josas area [25].

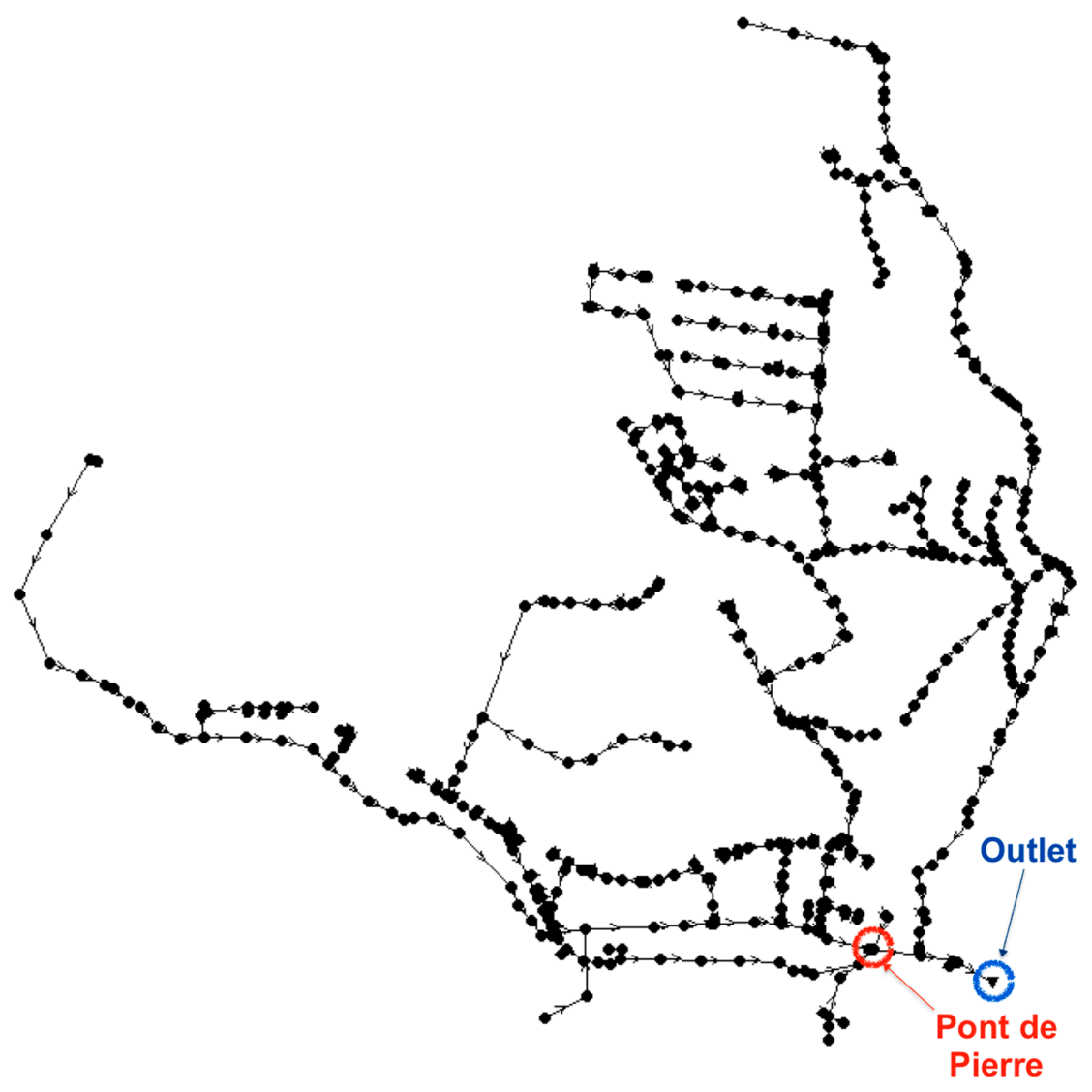

Figure 8. Sewer system network of Jouy-en-Josas area. 
Finally, there is a major modification in the rainfall generation code compared to that used by Gires et al. [25]. We identified that the mosaic C-band data [34,60] furnished by Météo-France (the French national meteorological service) has an irregular spatial distribution (see Figure 9), despite the fact that each data pixel has a $1 \mathrm{~km} \times 1 \mathrm{~km}$ square shape and is North-South oriented. The finer the model resolution, the greater the impact of this pixel spatial offset; therefore, we generated the rainfall rate input files by getting intersection contributions of the C-band radar data pixels to the $10 \mathrm{~m} \times 10 \mathrm{~m}$-sized model pixels (as in Equation (6)).

$$
R_{i_{10 m}, j_{10 m}}=\frac{\sum_{i_{1 k m}, j_{1 k m}}\left[R_{i_{1 k m}, j_{1 k m}} \cdot\left(A_{i_{10 m}, j_{10 m}} \cap A_{i_{1 k m}, j_{1 k m}}\right)\right]}{\sum_{i_{1 k m}, j_{1 k m}}\left(A_{i_{10 m}, j_{10 m}} \cap A_{i_{1 k m}, j_{1 k m}}\right)}
$$

where, $R_{i_{10 m}, j_{10 m}}$ is the rainfall rate that we want to calculate for each Multi-Hydro $10 \mathrm{~m} \times 10 \mathrm{~m}$-sized pixel; $R_{i_{1 \mathrm{~km}}, j_{1 \mathrm{~km}}}$ is the rainfall rate of each pixel of the C-band radar data; $A_{i_{10 \mathrm{~m}}, j_{10 \mathrm{~m}}}$ is the area of each Multi-Hydro pixel; and $A_{i_{1 k m}, j_{1 k m}}$ is the area of each pixel of the C-band radar data.

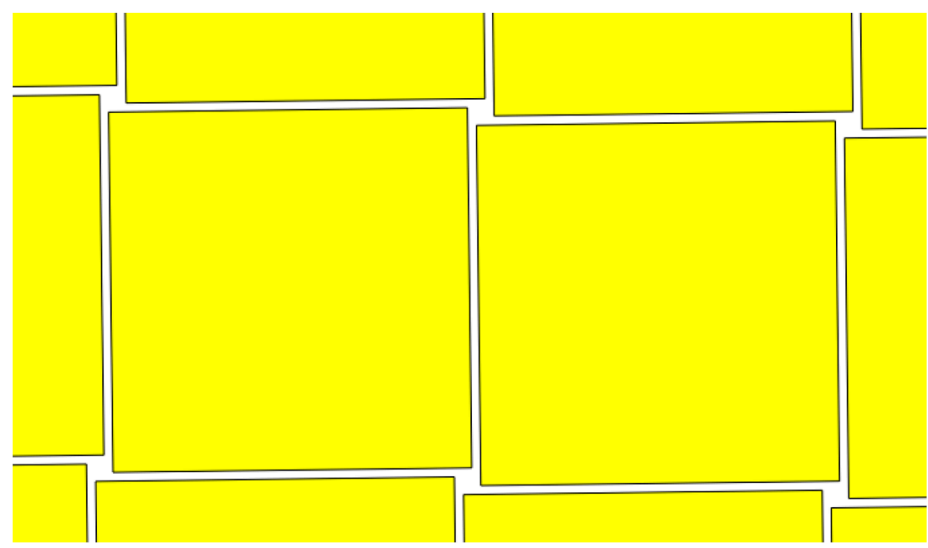

Figure 9. C-band radar data pixels distribution.

Thus, to generate the $\mathrm{X}$-band radar rainfall rate files, a process of getting intersection contributions to the aforementioned $10 \mathrm{~m} \times 10 \mathrm{~m}$-sized model pixels was applied. Nevertheless, in Equation (6), we changed $R_{i_{1 k m}, j_{1 k m}}$ by $R_{i_{250 m}, j_{250 m}}$ and $A_{i_{1 k m}, j_{1 k m}}$ by $A_{i_{250 m}, j_{250 m}}$, due to the resolution of the X-band radar data.

\subsubsection{Optim Sim/InfoWorks and the Bièvre Catchment}

The SIAVB cooperates with Veolia in managing the whole Bièvre catchment, by using an operational (previously calibrated with CALAMAR and SIAVB rain gauge rainfall data) semi-distributed model called Optim Sim [53]. It is an "offline" (disconnected to the system) simulation model which mimics the operation of the real-time optimization tool, and couples it to InfoWorks, matching its nodes and lines with InfoWorks' nodes and pipelines. Using the "simulation test mode", it is possible to replay past events with four rainfall data types (C-band radar data, X-band radar data, CALAMAR data or SIAVB rain gauge data) and to simulate each sub-catchment hydrological contribution for the whole catchment.

In this work, given the recent lack of local measurements at the Pont-de-Pierre, we used the flood depth contributions of the sub-catchment JOUY2 (corresponding to the Jouy-en-Josas fully-distributed sub-catchment) to compare to (and revalidate) those obtained with Multi-Hydro.

\subsection{Hydrological Simulations}

After preparing all the input data, Multi-Hydro was employed to simulate the three events using both C- and X-band radar rainfall data. Then, the hydrological results of the Multi-Hydro 
simulations without amount inflow were compared to the results of the Optim Sim simulations over the sub-catchment JOUY2, using the C-and X-band radar data, the CALAMAR product data and the SIAVB network of six rain gauges at the outlet of the catchment (Figures 10-12).

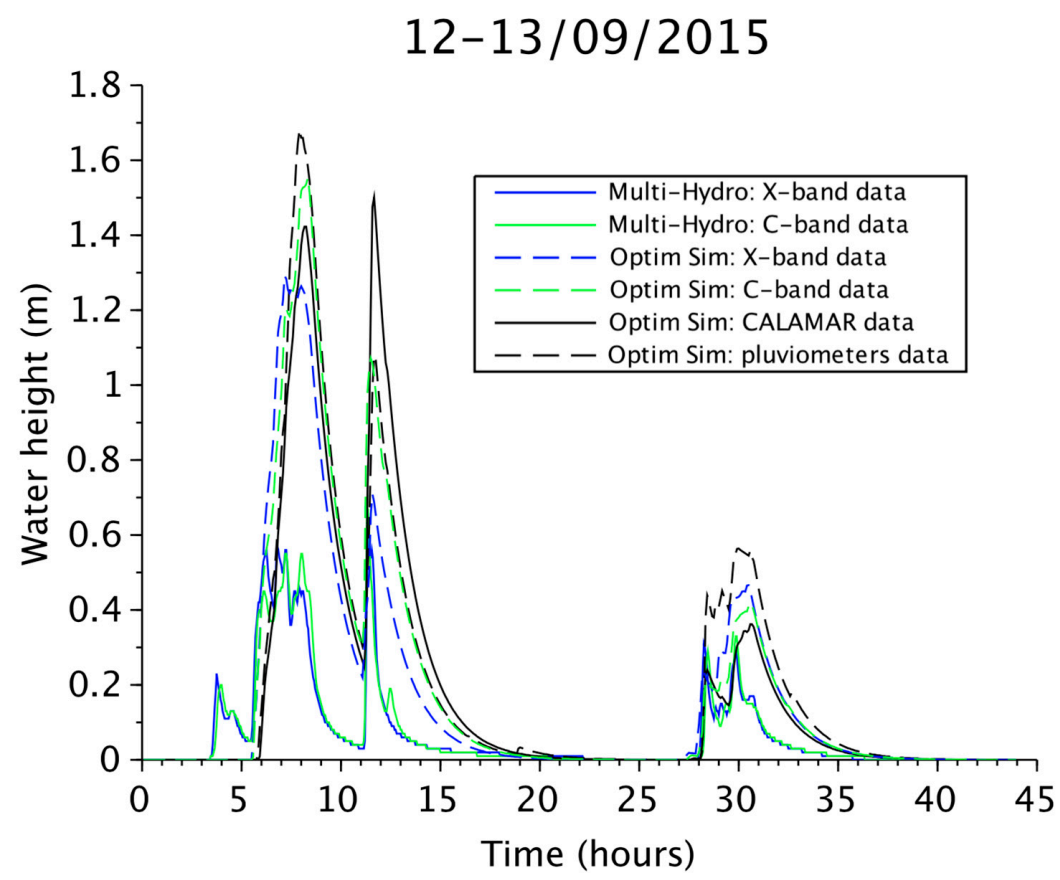

Figure 10. Comparison of Multi-Hydro water heights at the catchment outlet using X- (solid blue line) and C-band radar (solid green line) data compared to Optim Sim simulations with X-band radar (dashed blue line), C-band radar (dashed green line), CALAMAR (solid black line) and rain gauges (dashed black line) rainfall data for the 12/13-09-2015 event.

\section{$16 / 09 / 2015$}

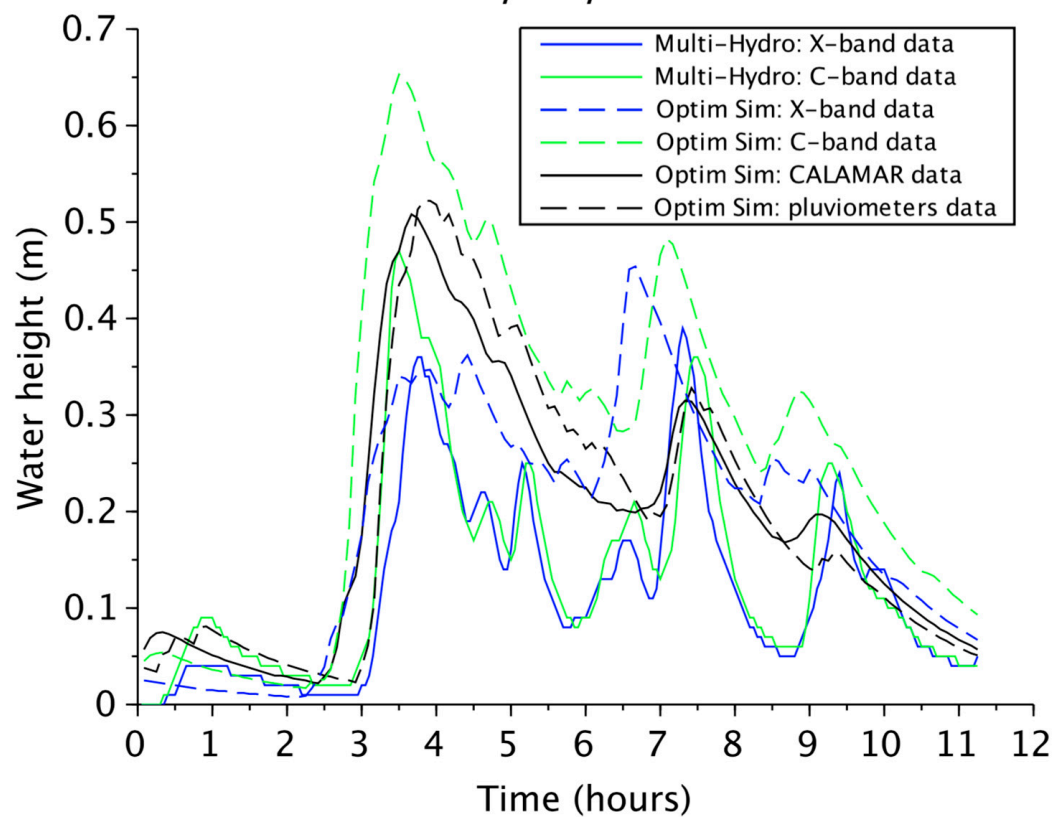

Figure 11. Comparison of Multi-Hydro water heights at the catchment outlet using $X$ - (solid blue line) and C-band radar (solid green line) data compared to Optim Sim simulations with X-band radar (dashed blue line), C-band radar (dashed green line), CALAMAR (solid black line) and rain gauges (dashed black line) rainfall data for the 16-09-2015 event. 


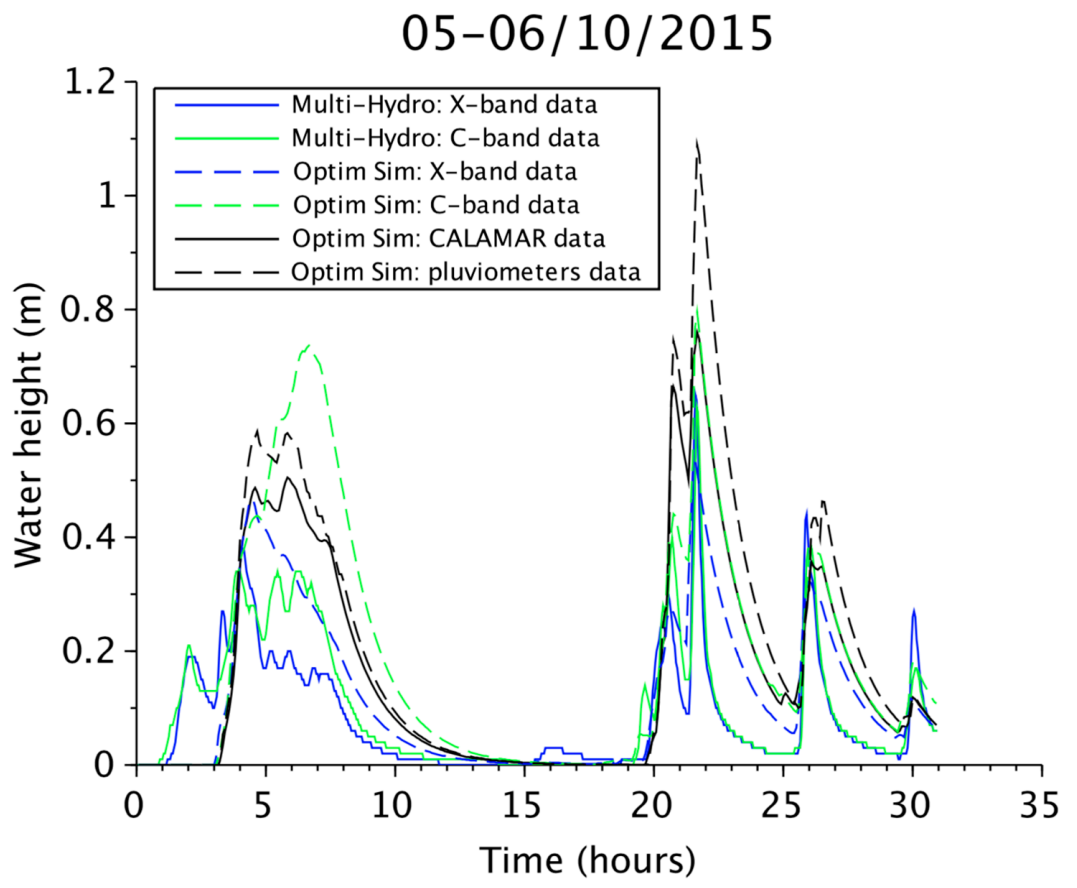

Figure 12. Comparison of Multi-Hydro water heights at the catchment's outlet using X- (solid blue line) and C-band radar (solid green line) data compared to Optim Sim simulations with X-band radar (dashed blue line), C-band radar (dashed green line), CALAMAR (solid black line) and rain gauges (dashed black line) rainfall data for the 05/06-10-2015 event.

One may note that the temporal evolution of the main peaks of the simulated water height is mostly in agreement for both models and for all data types. Given the lack of local measurements, and the fact that the semi-distributed model Optim Sim of the Bièvre catchment has been calibrated, these results seem to partially validate the fully-distributed model Multi-Hydro over the whole case study area. Nevertheless, the Multi-Hydro simulations present significantly higher variability, with a characteristic smoothing of the Optim Sim simulations, especially for the event of the 16 September 2015, which was expected because of the intrinsic averaging process for the rainfall data in the case of the semi-distributed model.

Furthermore, in order to statistically compare the hydrological results, we used three standard metric parameters: the correlation coefficient (Corr $\in[-1,1])$, the Nash-Sutcliffe Efficiency $($ Nash $\in(-\infty, 1])$ and the Root-Mean-Square Error (RMSE). Figure 13 presents the statistical analysis of all simulations for the three events, taking those performed with the CALAMAR rainfall data as references.

For the event of the 12-13 September 2015, the simulations using Multi-Hydro were very similar for both C- and X-band radar data, following the tiny difference of the total rainfall series (see Figure 4). By comparing to the Optim Sim simulations (especially those using the same C- and X-band radar data as Multi-Hydro), it was determined that in the first water height peak (from 6 to $10 \mathrm{~h}$ of the event duration) the Optim Sim simulations were higher than the Multi-Hydro ones; in the second peak (from 11 to $15 \mathrm{~h}$ of the event duration), the Optim Sim X-band simulation was closer to the Multi-Hydro one, while the Optim Sim C-band and pluviometers simulations were similar to each other and higher than both Multi-Hydro simulations; finally, the Optim Sim CALAMAR simulation was the highest one. In the third and last peak (from 28 to $35 \mathrm{~h}$ of the event duration), all the Optim Sim simulations were similar and slightly higher than the Multi-Hydro ones. This analysis is corroborated by the statistical one when the Optim Sim CALAMAR simulations are taken as the basis of comparison. Both Multi-Hydro simulations present medium values of correlation $(0.6<$ Corr $<0.8)$, Nash-Sutcliffe Efficiency $(0.2<$ Nash $<0.3)$ and Root-Mean-Square Error $(0.25<$ RMSE $<0.3)$. On the other hand, the statistical comparisons for the other three Optim Sim simulations (using $X-$ and 
C-band radar and rain gauge rainfall data) obtained better values $(0.85<$ Corr $<1 ; 0.7<$ Nash $<1$ and $0.09<$ RMSE $<0.17$ ); this was expected, since these simulations were performed with the same hydrological model as that used as a basis.
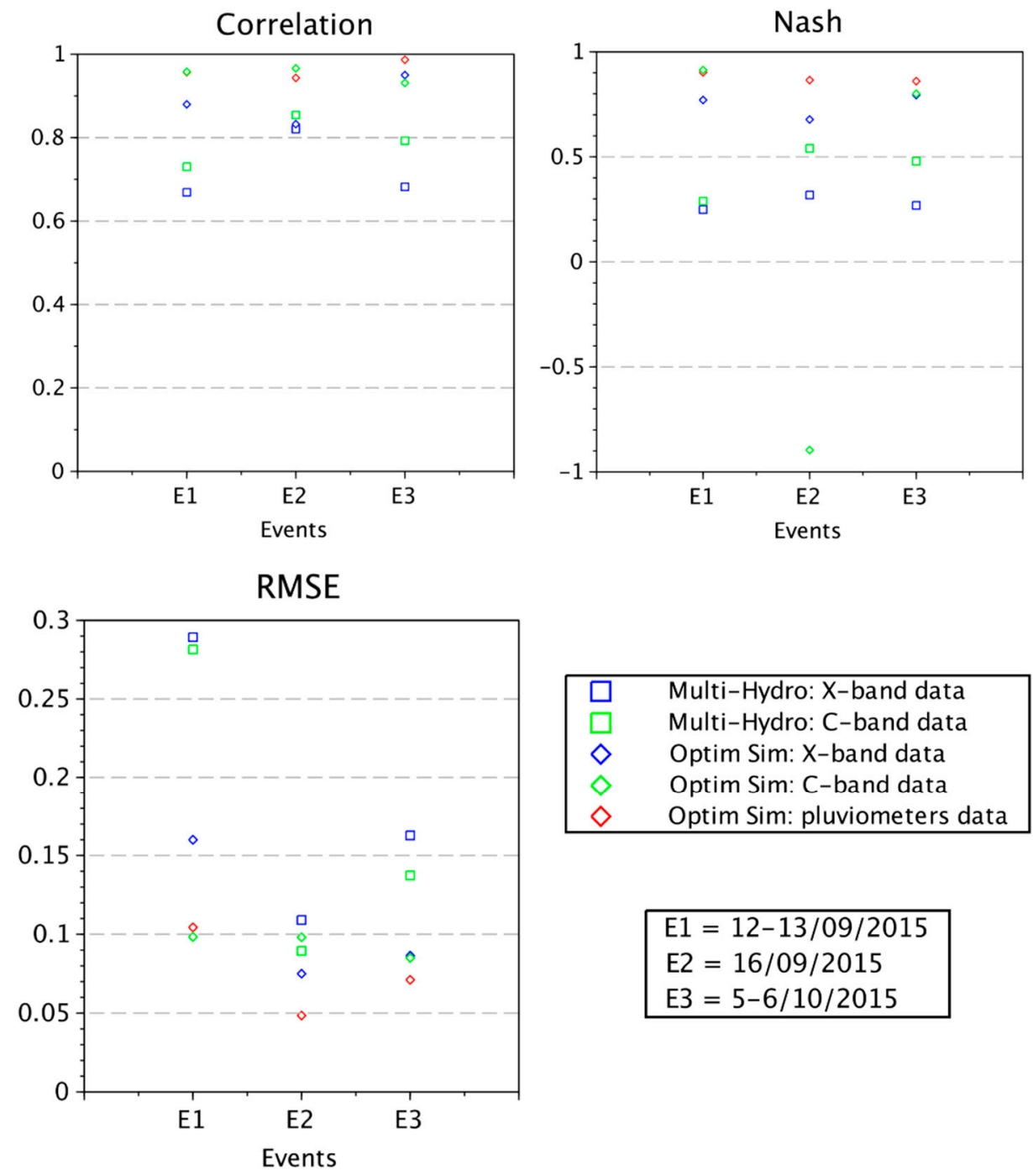

$$
\begin{aligned}
& \mathrm{E} 1=12-13 / 09 / 2015 \\
& \mathrm{E} 2=16 / 09 / 2015 \\
& \mathrm{E} 3=5-6 / 10 / 2015
\end{aligned}
$$

Figure 13. Statistical analysis of all hydrological results, with respect to the simulations using the CALAMAR rainfall data for the three studied events.

For the 16 September 2015 event, the Multi-Hydro simulations match each other very well along the whole event, with a slight difference in the first peak (between 3 and $4 \mathrm{~h}$ of the event duration) where the simulated water height was a bit higher for the C-band than for the X-band (following the total rainfall difference; see Figure 4). When comparing with the Optim Sim simulations, there was a greater difference between both C-band water heights compared to the X-band ones. In addition, compared to the Optim Sim simulations obtained using CALAMAR and pluviometers data (for which the model was calibrated), the Multi-Hydro simulations were more coherent than the Optim Sim ones using C- and X-band radar data. Furthermore, between the first two Optim Sim water height peaks (from 3 to $8 \mathrm{~h}$ of the event duration), the Multi-Hydro simulations present intermediary peaks (which is in agreement with the total rainfall series presented in Figure 4), whereas they were smoothed by the Optim Sim simulations, which highlights the higher capacity of the fully-distributed model Multi-Hydro to take into account rainfall spatio-temporal variability. When taking the Optim Sim simulations using CALAMAR rainfall data as a reference for the statistical comparison, one may note a high overall correlation (Corr $>0.8)$ and small Root-Mean-Square Errors $(0.04<$ RMSE $<0.12)$ in all 
simulations. Nevertheless, the Nash-Sutcliffe Efficiency estimated for the Optim Sim simulation using the $\mathrm{C}$-band radar data was very small (Nash $\approx-0.9$ ), whereas the other simulations presented better values $(0.25<$ Nash $<0.9)$.

Finally, for the event of 5-6 October 2015, the Multi-Hydro simulated water heights are slightly higher on average for the C-band radar in the first peak, which is also related to the need of a better choice of the $a-b$ parameters for low intensities in the X-band radar data (see the total rainfall difference in Figure 4), whereas the last peaks are marginally higher for the X-band radar data. In comparing to the Optim Sim simulations, in the first water height peak, the Optim Sim simulations were a bit higher than the Multi-Hydro ones, with both X-band simulations matching better to each other than the C-band ones. At the end of the event (second and third peaks), the simulated water heights were comparable between both models with great matching, alternating which one was providing the highest values, except for the rain gauge simulations between 20 and $23 \mathrm{~h}$, which are a bit higher than the others. The statistical analysis of these hydrological simulations, taking those using CALAMAR rainfall data as basis of comparison, confirms the presented results. Similar to the first event, the Multi-Hydro simulations also displayed intermediary values of correlation $(0.6<$ Corr $<0.8)$ and Nash-Sutcliffe Efficiency $(0.2<$ Nash < 0.5). Nevertheless, the Root-Mean-Square Error obtained $(0.13<\mathrm{RMSE}<0.17)$ was significantly better than that of the first event. Furthermore, the other three Optim Sim simulations (using $\mathrm{X}$-band radar, $\mathrm{C}$-band radar and rain gauge rainfall data) presented better statistical values $(0.9<$ Corr $<1 ; 0.7<$ Nash $<0.9$ and $0.06<$ RMSE $<0.09)$, as expected.

\section{Discussions}

The Jouy-en-Josas catchment, a $3 \mathrm{~km}^{2}$, semi-urbanized area located in the southwest region of Paris, was modelled with the physically-based, fully-distributed model Multi-Hydro using as rainfall inputs both Météo-France C-band radar data, at a $1 \mathrm{~km} \times 1 \mathrm{~km} \times 5 \mathrm{~min}$ resolution, and the ENPC dual-polarized X-band radar data, at a resolution of $250 \mathrm{~m} \times 250 \mathrm{~m} \times 3.41 \mathrm{~min}$. The results were then compared to the hydrological simulations obtained with the operational hydrological software Optim Sim (based on the conceptually-based semi-distributed model InfoWorks) using four different sources of rainfall data: the Météo-France C-band radar data, the ENPC X-band radar data, the CALAMAR $\mathrm{C}$-band radar product and the SIAVB network of six rain gauges. The main objectives in this paper were: (i) to find a way to compare the fully-distributed physically based Multi-Hydro model and the semi-distributed conceptually based Optim Sim model, over a semi-urban area with steep slopes; (ii) to improve and revalidate the Multi-Hydro modelling of the catchment by considering the totality of the catchment sewer system; and (iii) to analyze the impact of rainfall spatio-temporal variability using Cand $\mathrm{X}$-band radar data at different resolutions.

The difficulties associated with performing really accurate hydrological modelling were evident in this work, mostly due to model limitations and data quality and resolution. Two types of deterministic hydrological models were studied here. Semi-distributed conceptual models (represented here by Optim Sim/InfoWorks) present evident difficulties when taking into account the spatial variability of weather radar data, averaging them over big (sub-catchment) areas and consequently smoothing the hydrological results. Furthermore, they need exhaustive calibrations to be performed after each modification of the sub-catchment division or of the sewer system, or even after important land-use changes. Additionally, the size (and/or number) of the sub-catchments is questionable, relative to the type and resolution of rainfall data used as the input to the model [31]. On the other hand, fully-distributed physical models (e.g., Multi-Hydro) can better consider the spatial variability of the rainfall data, as they use information (such as topography, land use etc.) distributed in pixels, making spatial resolution adaptation possible, and take advantage of the use of physical measurable parameters to enhance the calibration process. Nevertheless, preparation of the input data requires complete information, especially for a complex sewer system. In this work, after performing the Multi-Hydro simulations considering the totality of the catchment's sewer system, and comparing 
with the Optim Sim simulations, it was possible to note higher intermittency and faster responses of the Multi-Hydro simulated heights.

Moreover, the rainfall data play a big role in the reliability of the hydrological simulations. The spatio-temporal resolution, the choice of the best products and data treatment are some of the factors that have an impact on the hydrological results. Throughout this paper, it was also possible to note that the Multi-Hydro simulations using the X-band radar rainfall data sometimes performed better, measuring higher peaks of rainfall rates and generating, in most cases, higher water heights, even without any absolute calibration, highlighting the advantages of better resolution. Furthermore, the X-band radar data simulations were able to generate water heights which were closer in both hydrological models, whereas the simulations using C-band radar data induced more differences between the models, which corroborates the impact of higher rainfall data resolutions. This was confirmed by the statistical analyses performed with the help of Universal Multifractals, where the estimated multifractality value $\alpha$ was considerably higher for the X-than for C-band radar data for all three events. However, there is an urgent need to study the best a-b parameters (see Equation (1)) to be used in each situation, as they directly impact low intensity estimates.

Finally, a different approach may be taken in the future: to merge deterministic (e.g., the fully-distributed physically-based Multi-Hydro model) and stochastic models (also named "empirical models", they directly relate the input data with the output results via a statistical way), would yield a hybrid model.

Author Contributions: I.P. wrote the paper; I.T., D.S. and B.T. conceived and designed the study; I.T. and D.S. collected the ENPC X-band radar data; B.W. and H.C. gave access to the Optim Sim hydrological model; I.P. prepared the input data for all simulations; I.P. and B.A.S. performed the Multi-Hydro simulations; B.W., I.P., A.G. and L.M. performed the Optim Sim hydrological simulations; I.P. performed the multifractal analyses; I.P., A.G., L.M., I.T. and D.S. analyzed all the results; B.W., A.G., B.A.S., L.M., H.C., B.T., I.T. and D.S. revised the paper.

Funding: This research was partially funded by the CHAIR "HYDROLOGY FOR RESILIENT CITIES" endowed by Veolia, and by the DEPARTMENT OF SCIENCE AND TECHNOLOGY OF THE BRAZILIAN ARMY.

Acknowledgments: The authors greatly acknowledge partial financial supports of the Chair "Hydrology for resilient cities" endowed by Veolia, and of the Department of Science and Technology of the Brazilian Army. The authors are thankful to M Bernard Urban (Météo-France) for providing access to the C-band radar data and documentation in the framework of the INTERREG NWE RainGain project.

Conflicts of Interest: The authors declare no conflict of interest. The funders had no role in the design of the study; in the collection, analyses, or interpretation of data; in the writing of the manuscript, or in the decision to publish the results.

\section{References}

1. United Nations, Department of Economic and Social Affairs. Population Division, World Urbanization Prospects: The 2014 Revision, CD-ROM Edition; United Nations, Department of Economic and Social Affairs: New York, NY, USA, 2014.

2. Sustainable Development Goals. Available online: https://sustainabledevelopment.un.org/?menu=1300 (accessed on 19 May 2016).

3. WHO Library Cataloguing-in-Publication Data. Global Report on Urban Health: Equitable, Healthier Cities for Sustainable Development; WHO: Geneva, Switzerland; UN-Habitat: Nairobi, Kenya, 2016; ISBN 978-92-4-156527-1.

4. IPCC. Climate Change 2014: Synthesis Report; Contribution of Working Groups I, II and III to the Fifth Assessment Report of the Intergovernmental Panel on Climate Change; Core Writing Team, Pachauri, R.K., Meyer, L.A., Eds.; IPCC: Geneva, Switzerland, 2014; 151p.

5. Burns, M.; Fletcher, T.D.; Hatt, B.E.; Ladson, A.; Walsh, C.J. Hydrologic shortcomings of conventional urban stormwater management and opportunities for reform. Landsc. Urban Plan. 2012, 105, 230-240. [CrossRef]

6. Furusho, C.; Andrieu, H.; Chancibault, K. Analysis of the hydrological behaviour of an urbanizing basin. Hydrol. Process. 2014, 28, 1809-1819. [CrossRef]

7. Schmitt, T.G.; Thomas, M.; Ettrich, N. Analysis and modeling of flooding in urban drainage systems. J. Hydrol. 2004, 299, 300-311. [CrossRef] 
8. Huang, H.J.; Cheng, S.J.; Wen, J.C. Effect of growing watershed imperviousness on hydrograph parameters and peak discharge. Hydrol. Process. 2008, 22, 2075-2085. [CrossRef]

9. Chen, J.; Arleen, A.H.; Lensyl, D.U. A GIS-based model for flood inundation. J. Hydrol. 2009, 373, $184-192$. [CrossRef]

10. Olang, L.O.; Furst, J. Effects of land cover change on flood peak discharges and runoff volumes: Model estimates for the Nyando River Basin, Kenya. Hydrol. Process. 2010, 25, 80-89. [CrossRef]

11. Salvadore, E.; Bronders, J.; Batelaan, O. Hydrological modelling of urbanized catchemnts: A review and future directions. J. Hydrol. 2015, 529, 62-81. [CrossRef]

12. Braud, I.; Fletcher, T.D.; Andrieu, H. Hydrology of peri-urban catchments: Processes and modelling. J. Hydrol. 2013, 485, 1-4. [CrossRef]

13. Fletcher, T.D.; Andrieu, H.; Hamel, P. Understanding, management and modelling of urban hydrology and its consequences for receiving waters; a state of the art. Adv. Water Resour. 2013, 51, 261-279. [CrossRef]

14. Niemczynowicz, J. Urban hydrology and water management - present and future challenges. Urban Water 1999, 1, 1-14. [CrossRef]

15. Price, R.K.; Vojinović, Z. Urban Hydroinformatics: Data, Models and Decision support for Integrated Urban Water Management; IWA Publishing: London, UK, 2011.

16. Schirmer, M.; Leschik, S.; Musolff, A. Current research in urban hydrogeology-A review. Adv. Water Resour. 2012, 51, 280-291. [CrossRef]

17. Ochoa-Rodriguez, S.; Wang, L.-P.; Gires, A.; Pina, R.; Reinoso-Rondinel, R.; Bruni, G.; Ichiba, A.; Gaitan, S.; Cristiano, E.; van Assel, J.; et al. Impact of spatial and temporal resolution of rainfall inputs on urban hydrodynamic modelling outputs: A multi-catchment investigation. J. Hydrol. 2015, 531, 389-407. [CrossRef]

18. Fabry, F.; Bellon, A.; Duncan, M.R.; Austin, G.L. High resolution rainfall measurements by radar for very small basins: The sampling problem reexamined. J. Hydrol. 1994, 161, 415-428. [CrossRef]

19. Berne, A.; Delrieu, G.; Creutin, J.-D.; Obled, C. Temporal and spatial resolution of rainfall measurements required for urban hydrology. J. Hydrol. 2004, 299, 166-179. [CrossRef]

20. Bringi, V.N.; Chandrasekar, V. Polarimetric Doppler Weather Radar: Principles and Applications; Cambridge University Press: Cambridge, UK, 2001.

21. Illingworth, A.J.; Blackman, T.M. The need to represent raindrop size spectra as normalized gamma distributions for the interpretation of polarization radar observations. J. Appl. Meteorol. 2002, 41, $286-297$. [CrossRef]

22. Figueras i Ventura, J.; Boumahmoud, A.-A.; Fradon, B.; Dupuy, P.; Tabary, P. Long-term monitoring of French polarimetric radar data quality and evaluation of several polarimetric quantitative precipitation estimators in ideal conditions for operational implementation at C-band. Q. J. R. Meteorol. Soc. 2012, 138, 2212-2228. [CrossRef]

23. Pina, R.; Ochoa-Rodríguez, S.; Simões, N.; Mijic, A.; Sa Marques, A.; Maksimovič, C. Semi-distributed or fully distributed rainfall-runoff models for urban pluvial flood modelling? Water 2016, 8, 58. [CrossRef]

24. Ichiba, A. X-Band Radar Data and Predictive Management in Urban Hydrology. Ph.D. Thesis, Earth Sciences, Université Paris-Est, Champs-sur-Marne, France, 2016.

25. Gires, A.; Abbes, J.-B.; Paz, I.S.R.; Tchiguirinskaia, I.; Schertzer, D. Multifractal characterisation of simulated surface flow: A case study with Multi-Hydro in Jouy-en-Josas, France. J. Hydrol. 2018, 558, 482-495. [CrossRef]

26. El-Tabach, E.; Tchiguirinskaia, I.; Mahmood, O.; Schertzer, D. Multi-Hydro: A Spatially Distributed Numerical Model to Assess and Manage Runoff Processes in Peri-Urban Watersheds. In Proceedings of the Road Map Towards a Flood Resilient Urban Environment, Paris, France, 26-27 November 2009; Pascheet, E., Evelpidou, N., Zevenbergen, C., Ashley, R., Garvin, S., Eds.; Hamburger Wasserbau-Schriftien: Hamburg, Germany, 2009.

27. Giangola-Murzyn, A. Modélisation et Paramétrisation Hydrologique de la ville, Résilience aux Inondations. Ph.D. Thesis, Earth Sciences, Université Paris-Est, Champs-sur-Marne, France, 2013.

28. Schertzer, D.; Lovejoy, S. Physical modelling and analysis of rain and clouds by anisotropic scaling multiplicative processes. J. Geophys. Res. 1987, D8, 9693-9714. [CrossRef]

29. Mellot, P. Paris inondé: Photographies JANVIER 1910; Éditions de Lodi: Midi Pyrénées, France, 2003; 208p.

30. RainGain Final Conference. Available online: http://www.raingain.eu/en/8-9-june-2015-raingain-finalconference-paris (accessed on 20 May 2016). 
31. Paz, I.; Willinger, B.; Gires, A.; Ichiba, A.; Monier, L.; Zobrist, C.; Tisserand, B.; Tchiguirinskaia, I.; Schertzer, D. Multifractal Comparison of Reflectivity and Polarimetric Rainfall Data from C-and X-Band Radars and Respective Hydrological Responses of a Complex Catchment Model. Water 2018, 10, 269. [CrossRef]

32. Parent du Châtelet, J. ARAMIS, le réseau Français de radars pour la surveillance des précipitations. La Météorologie 2003, 40, 44-52. [CrossRef]

33. Marshall, J.S.; Palmer, W.M.K. The distribution of raindrops with size. J. Meteorol. 1948, 5, 165-166. [CrossRef]

34. Tabary, P.; Boumahmoud, A.-A.; Andrieu, H.; Thompson, R.J.; Illingworth, A.J.; Le Bouar, E.; Testud, J. Evaluation of two "integrated" polarimetric Quantitative Precipitation Estimation (QPE) algorithms at C-band. J. Hydrol. 2011, 405, 248-260. [CrossRef]

35. Figueras i Ventura, J.; Tabary, P. The new French operational polarimetric radar rainfall rate product. J. Appl. Meteorol. Climatol. 2013, 52, 1817-1835. [CrossRef]

36. Selex. Selex METEOR Manual; Selex: Roman, Italy, 2015.

37. Keefe, P.; Stevens, P. CALAMAR and NEXRAD Dramatically Increase Accuracy of Urban Hydrology. In Proceedings of the WEF Annual Conference, Anaheim, CA, USA, 3-7 October 1993.

38. Stevens, P.; Lopez, M.; Jacquet, G. Evaluation of Gauge Adjusted Radar for Rainfall Measurement in RDII Programs. Glob. Solut. Urban Drain. 2002, 1-14. [CrossRef]

39. RHEA. Available online: http://www.rhea.tm.fr (accessed on 3 June 2016).

40. Ladoy, P.; Schmitt, F.; Schertzer, D.; Lovejoy, S. Variabilité temporelle multifractale des observations pluviométriques à Nîmes. C. R. Acad. Sci. II 1993, 317, 775-782.

41. Tessier, Y.; Lovejoy, S.; Schertzer, D. Universal multifractals in rain and clouds: Theory and observations. J. Appl. Meteorol. 1993, 32, 223-250. [CrossRef]

42. Tessier, Y.; Lovejoy, S.; Hubert, P.; Schertzer, D.; Pecknold, S. Multifractal analysis and modelling of rainfall and river flows and scaling, causal transfer functions. J. Geophys. Res. 1996, 101, 26427-26440. [CrossRef]

43. Olsson, J.; Niemczynowicz, J. Multifractal analysis of daily spatial rainfall distributions. J. Hydrol. 1996, 187, 29-43. [CrossRef]

44. de Lima, M.I.P.; Grasman, J. Multifractal analysis of 15-min and daily rainfall from a semi-arid region in Portugal. J. Hydrol. 1999, 220, 1-11. [CrossRef]

45. Deidda, R. Rainfall downscaling in a space-time multifractal framework. Water Resour. Res. 2000, 36, 1779-1794. [CrossRef]

46. Veneziano, D.; Langousis, A.; Furcolo, P. Multifractality and rainfall extremes: A review. Water Resour. Res. 2006, 42, W06D15. [CrossRef]

47. García-Marín, A.P.; Jiménez-Hornero, F.J.; Ayuso-Muñoz, J.L. Universal multifractal description of an hourly rainfall time series from a location in southern Spain. Atmósfera 2008, 21, 347-355.

48. Serinaldi, F. Multifractality, imperfect scaling and hydrological properties of rainfall time series simulated by continuous universal multifractal and discrete random cascade models. Nonlin. Process. Geophys. 2010, 17, 697-714. [CrossRef]

49. Gires, A.; Schertzer, D.; Tchiguirinskaia, I.; Lovejoy, S.; Onof, C.; Maksimovic, C.; Simoes, N. Impact of small scale rainfall uncertainty on urban discharge forecasts. In Proceedings of the Weather Radar and Hydrology, Exeter, UK, 27 April 2011; Moore, J., Cole, S., Illingworth, A., Eds.; IAHS Publ.: Exeter, UK, 2011; pp. 351, 400-406.

50. Tchiguirinskaia, I.; Schertzer, D.; Hoang, C.T.; Lovejoy, S. Multifractal study of three storms with different dynamics over the Paris region. In Proceedings of the Weather Radar and Hydrology, Exeter, UK, 27 April 2011; Moore, J., Cole, S., Illingworth, A., Eds.; IAHS Publ.: Exeter, UK, 2011; pp. 351, 421-426.

51. Rodríguez, R.; Casas, M.; Redaño, A. Multifractal analysis of the rainfall time distribution on the metropolitan area of Barcelona (Spain). Meteorol. Atmos. Phys. 2013, 121, 181-187. [CrossRef]

52. Hoang, C.-T.; Tchiguirinskaia, I.; Schertzer, D.; Lovejoy, S. Caractéristiques multifractales et extrêmes de la précipitation à haute resolution, application à la détection du changement climatique. Revue des Sciences de l'Eau-J. Water Sci. 2014, 27, 205-216. [CrossRef]

53. Paz, I.S.R. Quantifying the Rain Heterogeneity by X-Band Radar Measurements for Improving Flood Forecasting. Ph.D. Thesis, Université Paris-Est, Champs-sur-Marne, France, 2018.

54. Parisi, G.; Frisch, U. A multifractal model of intermittency. In Turbulence and Predictability in Geophysical Fluid Dynamics and Climate Dynamics; Ghil, M., Benzi, R., Parisi, G., Eds.; North-Holland: Amsterdam, The Netherlands, 1985; pp. 84-88. 
55. Lavallée, D.; Lovejoy, S.; Schertzer, D.; Ladoy, P. Nonlinear variability and landscape topography: Analysis and simulation. In Fractals in Geography; De Cola, L., Lam, N., Eds.; Prentice-Hall: Upper Saddle River, NJ, USA, 1993; pp. 171-205.

56. Alves de Souza, B.; da Silva Rocha Paz, I.; Ichiba, A.; Willinger, B.; Gires, A.; Amorim, J.C.C.; de Miranda Reis, M.; Tisserand, B.; Tchiguirinskaia, I.; Schertzer, D. Multi-hydro hydrological modelling of a complex peri-urban catchment with storage basins comparing C-band and X-band radar rainfall data. Hydrol. Sci. J. 2018, 63, 1619-1635. [CrossRef]

57. Velleux, M.L.; England, J.F.; Julien, P.Y. TREX Watershed Modelling Framework User's Manual: Model Theory and Description; Department of Civil Engineering, Colorado, State University: Fort Collins, CO, USA, 2011; 106p.

58. Lappala, E.G.; Healy, R.W.; Weeks, E.P. Documentation of Computer Program VS2D to Solve the Equations of Fluid Flow in Variably Saturated Porous Media; Water-Resources Investigations Report 83-4099; U.S. Geological Survey: Reston, VA, USA, 1987; 184p.

59. Rossman, L.A. Storm Water Management Model, User's Manual, Version 5.0; EPA/600/R-05/040; U.S. Environmental Protection Agency: Washington, DC, USA, 2010.

60. Tabary, P. The new French operational radar rainfall product. Part I: Methodology. Weather Forecast. 2007, 22, 393-408. [CrossRef]

(C) 2019 by the authors. Licensee MDPI, Basel, Switzerland. This article is an open access article distributed under the terms and conditions of the Creative Commons Attribution (CC BY) license (http://creativecommons.org/licenses/by/4.0/). 